\title{
Why public health must contribute to reduce violence
}

\author{
V Sivarajasingam reader, J P Shepherd professor, R G Newcombe professor \\ Violence and Society Research Group, School of Dentistry, Cardiff University, Cardiff CF14 4XY, UK
}

Florence and colleagues found that systematic collection, analysis, and use of anonymised emergency department recorded information on violence significantly reduced violence related hospital admissions. ${ }^{1}$

Although violence has long been a public health matter, there is ambivalence in making it a health priority. After all, crime reduction is the responsibility of government departments other than health, and other public services - the police, courts, and probation and prison services-are there to tackle it.

It has been known for some time that police records underestimate serious community violence and that emergency department injury records are more representative. We suggest that data matching studies in Denmark and Norway indicate that the extent to which serious violence is under-ascertained by police services is consistent across Europe. ${ }^{2}{ }^{3}$

Data matching (between emergency department and police violence records) from three north European countries has shown that on average the police record a third or less of violence that results in emergency department treatment. ${ }^{4}$ The main reasons for under-recording have been identified in the UK, and these factors may exert a remarkably similar influence across national boundaries.

There are important policy implications - that police data are a poor measure of serious violence; that health services provide information about violence that is not available elsewhere; and that violence in a city, for example, can be understood and targeted only if police and health data are combined. Such an approach, together with involvement of trauma service doctors in community safety partnerships, is proving effective, particularly by directing police activity. ${ }^{5}$ Public health and trauma services have much to contribute to violence prevention across Europe.

\section{Competing interests: None declared}

1 Florence C, Shepherd J, Brennan I, Simon T. Effectiveness of anonymised information sharing and use in health service, police, and local government partnership for preventing violence related injury: experimental study and time series analysis. BMJ 2011;342:d3313. (16 June.)

2 Faergemann C. Interpersonal violence in the Odense municipality, Denmark 1991-2002. $\mathrm{PhD}$ thesis. University of Southern Denmark, 2006.

3 Brink $\mathrm{O}$, Sorensen $\mathrm{V}$. Is the dark figure of violence decreasing? Nordisk Tidsskriff for Kriminalvidenskab 2001;88:230-9.

4 Sivarajasingam V, Shepherd JP, Newcombe RG. Violence prevention: why public health must contribute [electronic response to Florence $\mathrm{C}$, et al. Effectiveness of anonymised information sharing and use in health service, police, and local government partnership for preventing violence related injury: experimental study and time series analysis]. BMJ 2011. www.bmj.com/content/342/bmj.d3313/reply\#tbmj_el_264774?sid=c5edb1e3-9e204f8b-9d51-3727f2d8670f.

5 Warburton AL, Shepherd JP. Tackling alcohol related violence in city centres: effect of emergency medicine and police intervention. Emerg Med J 2006;23:12-7. 